Original article

https://www.journal-imab-bg.org

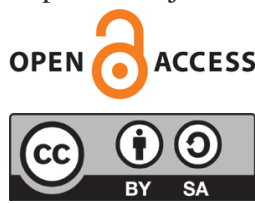

\title{
BIOMECHANICAL PRINCIPLES OF SHOULDER JOINT AS A BASIS OF POST FRACTURE ENDOPROSTHESIS REPLACEMENT
}

\author{
Ivaylo Mitkovski \\ Orthopaedics and Traumatology Department, St. Anna General Active Treatment \\ Hospital, Orthopaedics and Traumatology Department, Medical University- \\ Varna, Bulgaria.
}

\begin{abstract}
This article aims to present our academic knowledge in the shoulder joint biomechanics as a basis for post fracture endoprosthetis replacement.

MATERIALS AND METHODS: The post fracture trauma type and the dislocation degree are the two causes for often unsatisfactory results of the treatment because of pain, limited motions and loss of strength. In order to restore the anatomy as much possible and as closely to normal, blood reposition with internal fixation is the method of choice for any unstable fractures. Surgical treatment, however, is difficult and problematic because of the difficult access to the fracture and the large fragmentation of pieces.
\end{abstract}

A proximal shoulder bone fracture, which disturbs blood supply of the humeral head, may require placement of a prosthesis. Hemiarthroplastics is a logical approach in such cases, but the analysis of functional results and complications determines a certain number of risk factors, limiting the indications. A strict analysis of the patient characteristics and the fracture type is an essential precondition for making a decision against treatment by immobilization or by osteosynthesis. The results in hemiarthroplastics depend mainly on sticking to appropriate surgical practices, aimed at a stable anatomic osteosynthesis of the surrounding structures so that the normal shoulder function can be restored. Correcting the implant height and retroversion, reducing and fixing the tubercles and the good management of the post operative progress is crucial. Rapid development and manufacture of various types of shoulder implants lead to a significant improvement of results in fracture treatment. In elderly patients, when local conditions are not suitable for hemiarthroplastics, a reverse prosthesis can be used with adjusted surgical technique. Regardless of the prosthesis type, implanting in proximal shoulder bone fracture is an exigent operation with a certain impact on the functional shoulder development.

After the Neer report in 1970 about the shoulder prosthesis replacement results in proximal shoulder bone fracture, several attempts have been made to reproduce its encouraging initial findings. Many of them have shown good results regarding the pain, but a lot less satisfactory functional result.
CONCLUSION: Knowing the shoulder joint biomechanics is the basis for adequate preoperative planning, for choosing the technique for post fracture endoprosthesis replacement and prescribing an optimal rehabilitation program.

Keywords: Humeral Fractures, Shoulder Replacement Arthroplasty, Joints, Dislocation Fracture, Shoulder Prosthesis, Biomechanical Principles of Shoulder Joint, \section{JOINT \\ CLINICAL ANATOMY OF THE SHOULDER}

The glenohumeral joint is a real anatomic joint, which is formed by the humerus head and cavitasglenoidalis of the scapula [1, 2, 3] (Fig. 1). The humerus head is $1 / 3$ of a sphere with a diameter of $30 \mathrm{~mm}$, oriented upward medially and backward. This head encloses a $130-150^{\circ}$ angle with the diaphysis and is situated in retroversion towards the frontal plan of $20-30^{\circ}$. The head is separated from the diaphysis by an anatomic neck. The large tubercle is located laterally, and the small tubercle is located in front of it. They are separated from the sulcus with the biceps long head tendon.

Fig. 1. Glenohumeral Joint

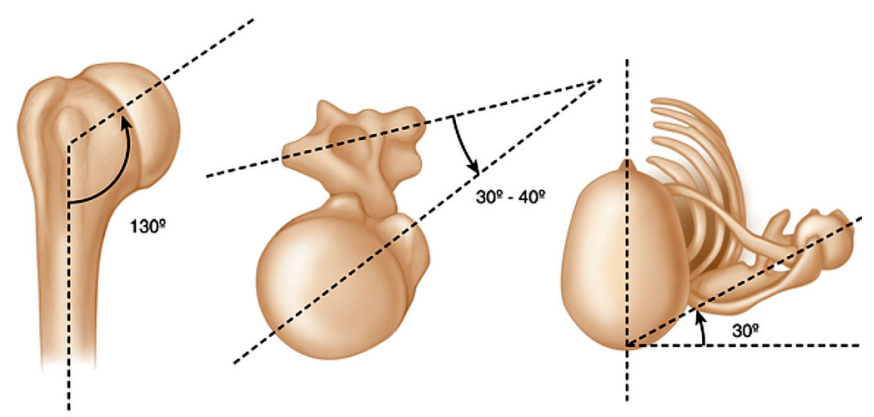

Cavitasglenoidalis is located in the upper external corner of the scapula and is faced onwards, upwards and to the sides (Fig. 2). It has a pear-shaped form because its upper part is narrower than the lower part and is biconcave, 
but the concavity does not correspond to the humerus head convexity. Its vertical size is $35 \mathrm{~mm}$, and its longitudinal size is $25 \mathrm{~mm}$ averagely. The glenoid may be in anteversion or in retroversion. It is determined [4] that in $75 \%$ of shoulders, it is in retroversion and in only $25 \%$ - in anteversion. Its vertical slope is $15^{\circ}$ medially of the scapula plan.

Fig. 2. Cavitas Glenoidalis and LabrumGlenoidale

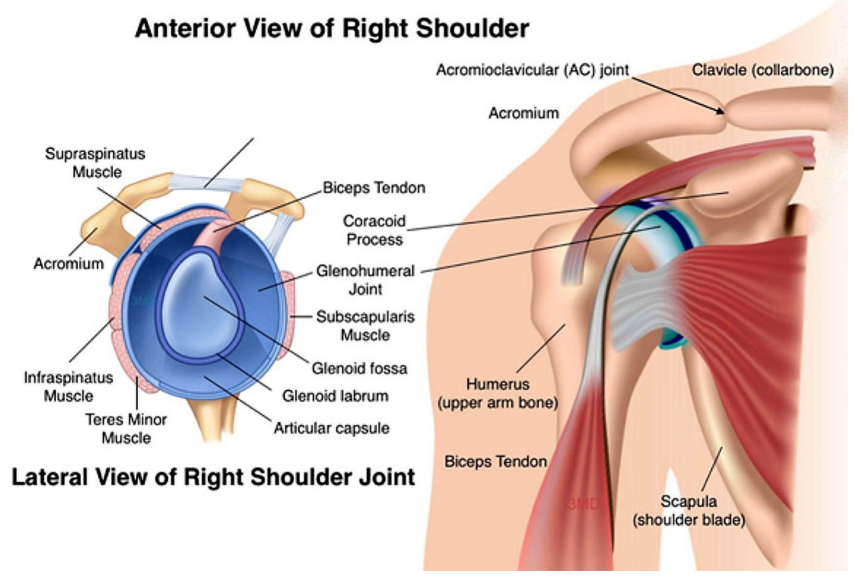

Labrumglenoidale (Fig. 2) is a fibrocartilaginous structure rim, which is attached along the cavitasglenoidalis periphery. Its transverse cut has a triangular shape. Its periphery serves for a ligament attachment. In its upper part, the glenoid labrum is not entirely fixed to the bone, and its internal end hangs freely in the joint cavity as a meniscus. The glenoid labrum deepens rather than expands the glenoid cavity in order to make it more congruent to the humerus head and thus contributes to the joint stability.

The joint capsule is large and is attached to the labrum and the scapula neck (Fig. 3). It reaches to the humerus anatomic neck. Inside, the capsule is covered by synovia and is loose enough so that the arm can be abducted. The capsule is strengthened by the tendons of the rotator cuff muscles on all sides, except of its lower part. The tendons of these muscles (supraspinatus, infraspinatus, teres minor and subcapsularis) are joined to the capsule to approximately $2.5 \mathrm{~cm}$ of its insertion places.

Fig. 3. The Tendons of Muscles Supraspinatus, Infraspinatus, Teres Minor And Subcapsularis

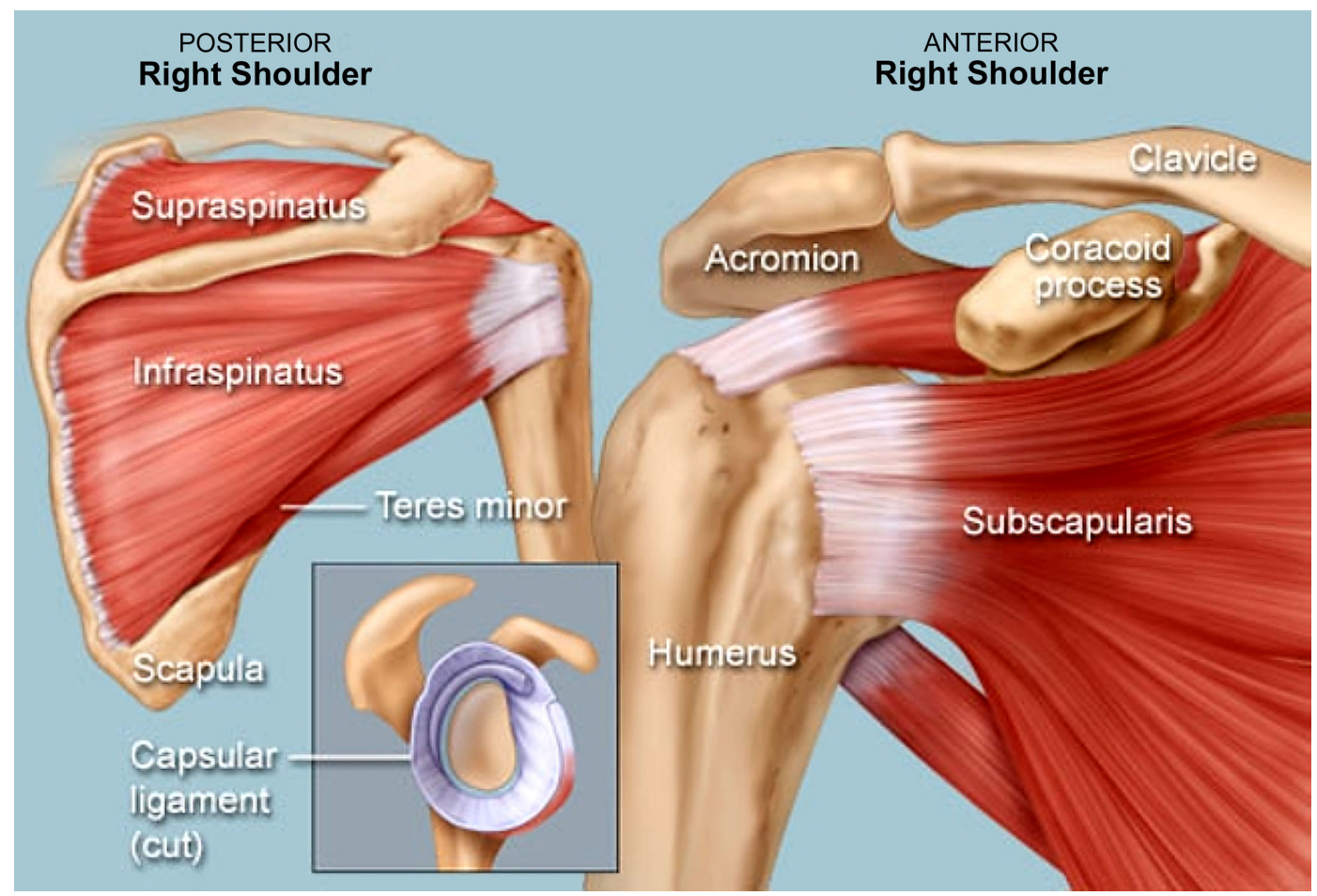

7 or 8 bursas are located around the shoulder [3] (Fig. 4). They create the so called "physiological joint" of the shoulder, which represents two surfaces, moving one towards the other. 
Fig. 4. Bursas Around the Shoulder

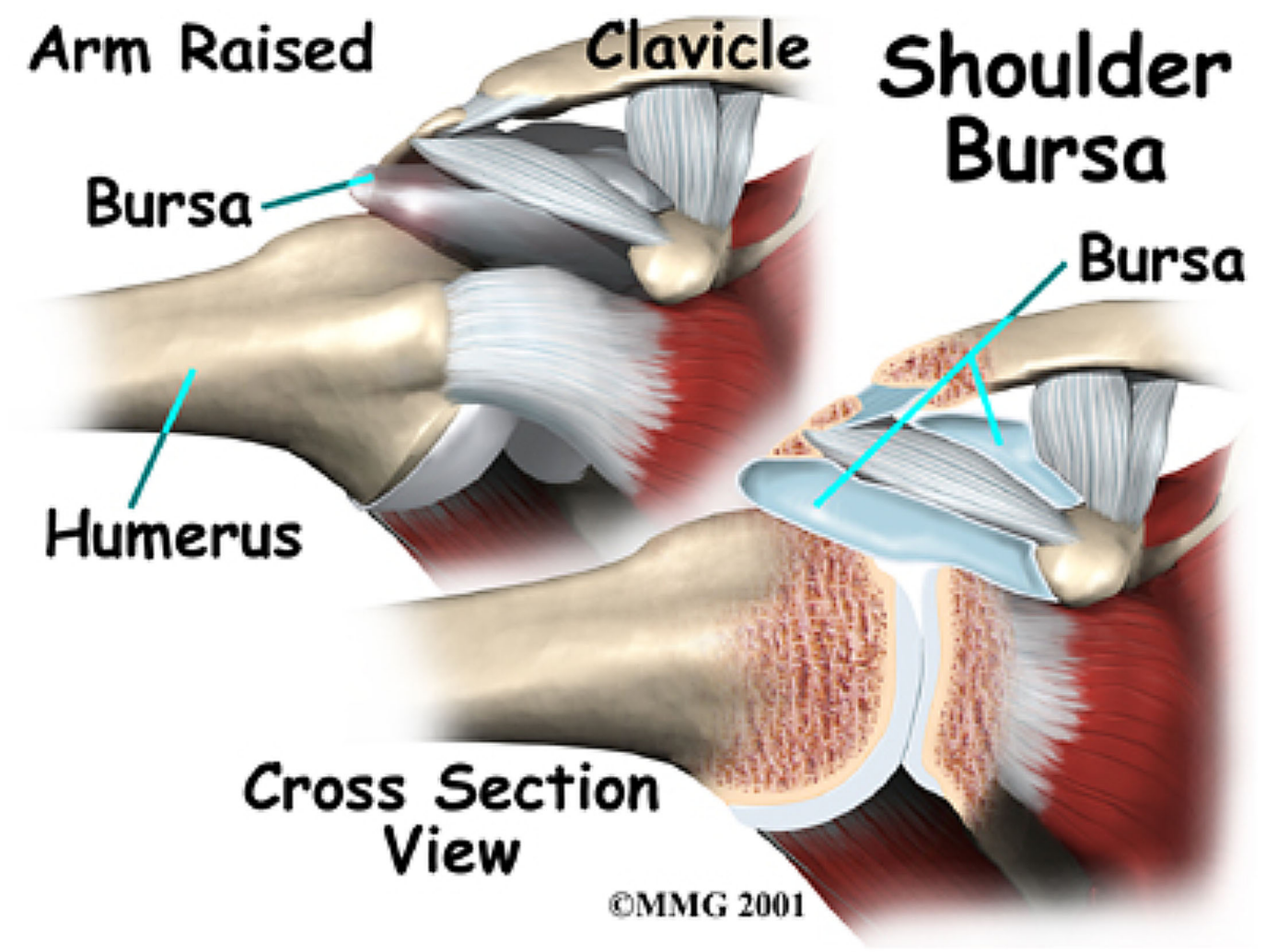

Blood supply of the humeral head is delivered mainly by the Laing's arcuate artery, the posterior and anterior circumflex arteries which come from the axillary artery [5] (Fig. 5).

Fig. 5. Blood Supply of the Humeral Head

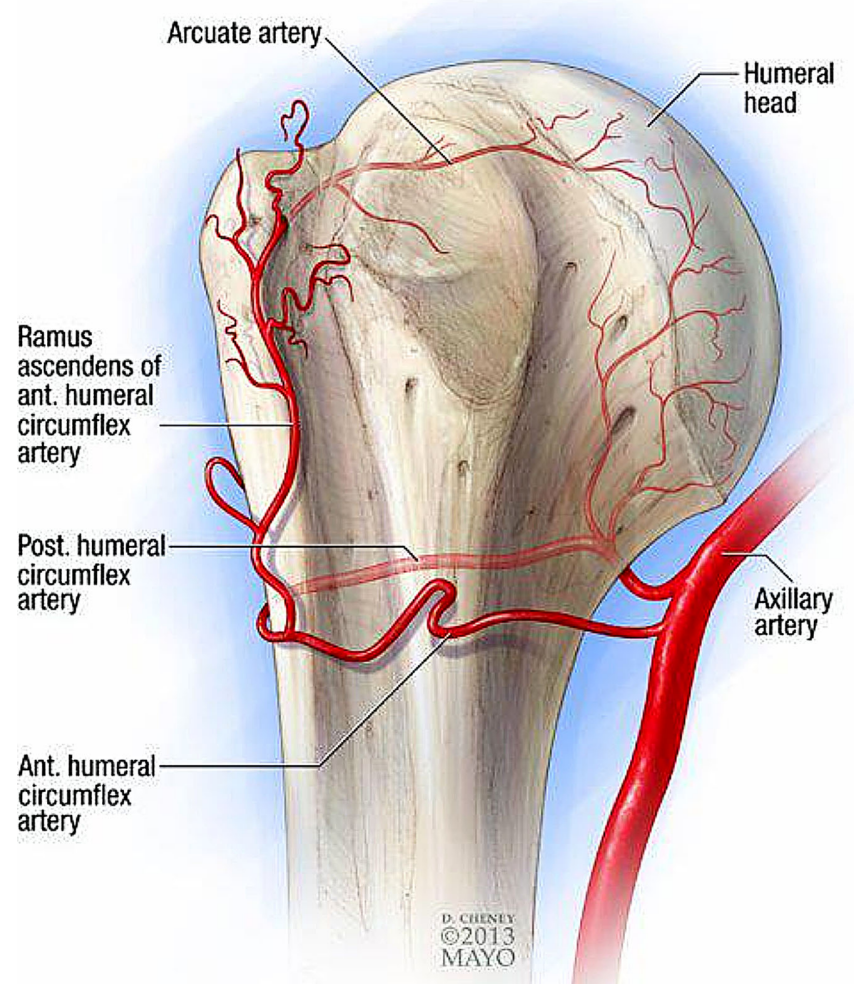

The superficial and deep shoulder innervation is performed by branches coming mainly from C5, C6 and C7, as well as from the following nerves: axillaris, suprascapularis, subscapularis and musculocutaneus.

\section{DER JOINT \\ CLINICAL BIOMECHANICS OF THE SHOUL-}

Joint surfaces adaptation is obtained by the action of muscles around the joint. Those passing transversely to the joint, pull the humerus head against the joint glenoid cavity. From the back, there pass the supraspinatus, infraspinatus and teres minor muscles. From the front, there passes musculus subscapularis, and above - the tendon of the biceps long head. Long muscles of the head and shoulder are always toned and prevent the infraglenoid luxation. The joint geometry is such that allows a larger volume of motions - the shoulder is the most mobile joint in the human body. This, however, is achieved on account of the joint biomechanical stability, because the relatively large humerus head articulates with the small and shallow glenoid cavity of the scapula.

Shoulder motions are performed in three plains horizontal, sagittal and frontal (Fig. 6). 
Fig. 6. Shoulder Motions Plains

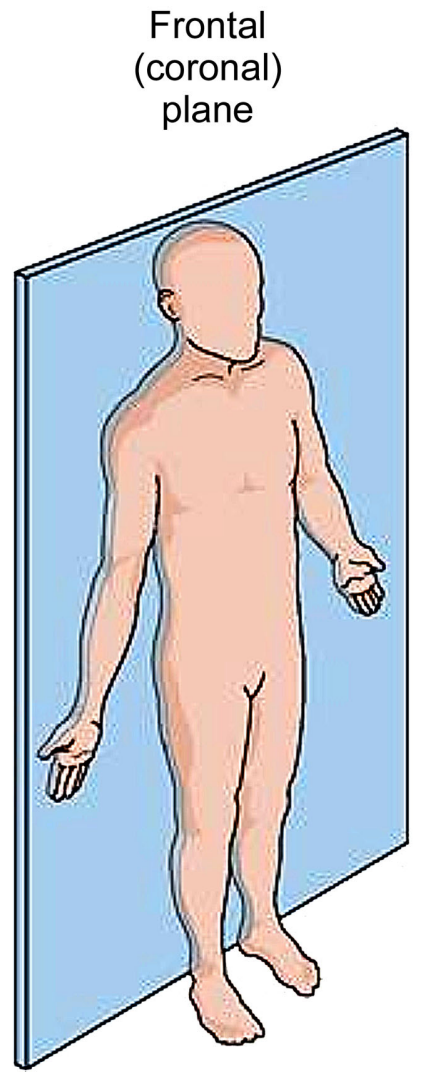

In a sagittal plan, extension of $45-50^{\circ}$ and flexion of $180^{\circ}$ are performed. In a frontal plan, adduction of 30$45^{\circ}$ and abduction of $180^{\circ}$ are performed. The rotation is performed around the longitudinal axis and is $80^{\circ}$ in an outward direction, whereas in the inward direction it is up to $95^{\circ}$.The shoulder's functional position is $45^{\circ}$ of flexion and $60^{\circ}$ of abduction, without rotation.

The arm elevation from the beginning to the end is smooth, continuous and rhythmic motion. All joints of the shoulder girdle take part in it: glenohumeral, sternoclavicular, acromioclavicular, scapulothoracic and physiological. This complex motion is called "scapulothoracic rhythm" by Codman [6]. The Codman paradox consists of the following (Fig. 7): the arm's starting position is next to the body, whereas the palm faces inwards to the hip, and the thumb faces forwards. From this position, the arm starts its motion aside and upwards to $180^{\circ}$. At the end upside position, the palm faces to the outside and the thumb faces onward. After that, the arm starts going down forwards, and when the arm reaches to the hip, it turns out so that the palm faces outwards, and the thumb faces backwards, which is opposite to the initial position. Hence, the palm changes its position during this motion and rotates. This $180^{\circ}$ rotation is performed automatically and shows that the motion, except around both axes, is performed also around a third axis.

\section{Transverse \\ (horizontal) \\ plane}

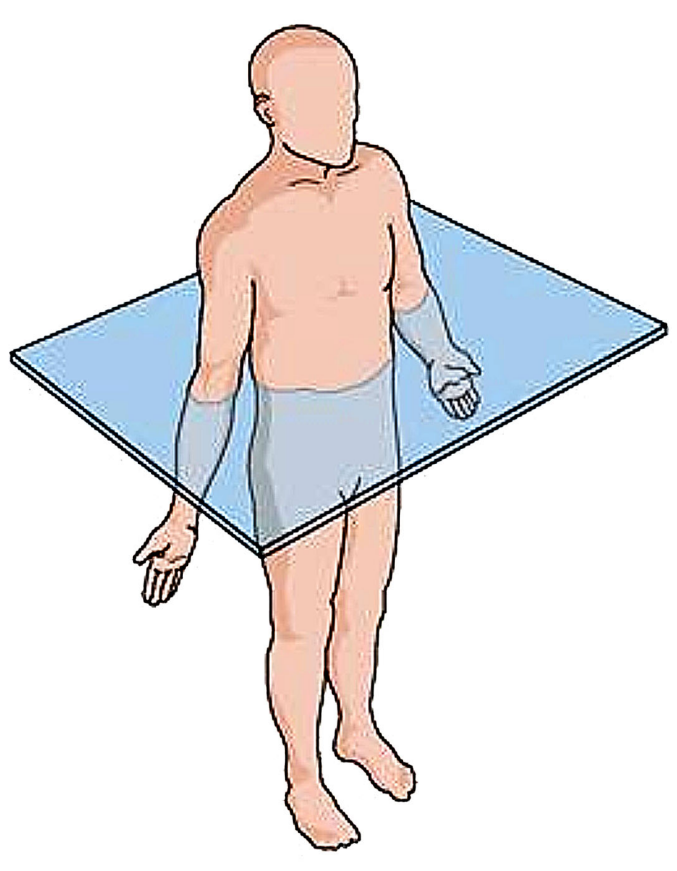

Fig. 7. The Codman Paradox

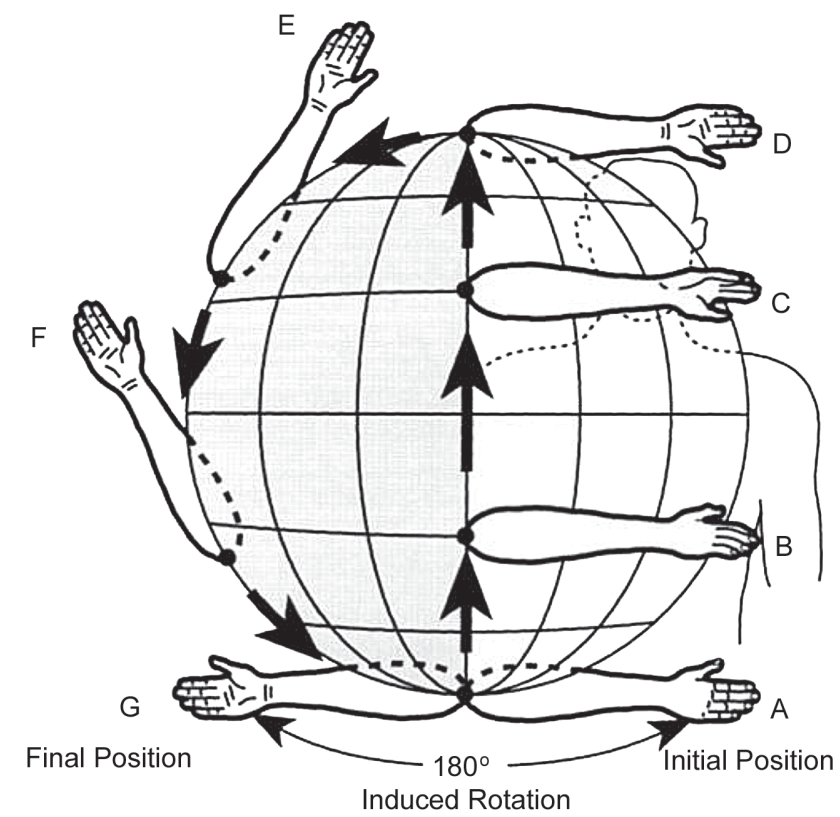

The most important shoulder function is the arm elevation (Fig. 8), for which all joints contribute [7, 8, 9, 10]. At the start of the abduction, the deltoideus virtually does not take place. In the position where the arm is next to the body, the supraspinatus is strained to the maximum. Therefore, at the beginning of the abduction, the supraspinatus is very efficient and keeps the joint surfaces one against 
the other. This is the "starter" muscle of the abduction. Once the abduction has started, the situation turns round with respect to muscle efficiency. The supraspinatus becomes progressively ineffective as a result of its shortening at 45$60^{\circ}$ abduction. The deltoideus, however, becomes more ef- ficient and performs the main part of the abduction. Its efficiency increases at $90^{\circ}$ of abduction. Hence, the first $30^{\circ}$ of the abduction are performed in the glenohumeral joint, whereas the motion correlation between this joint and the scapulothoracic joints is $7: 1$.

Fig. 8. The Arm Elevation

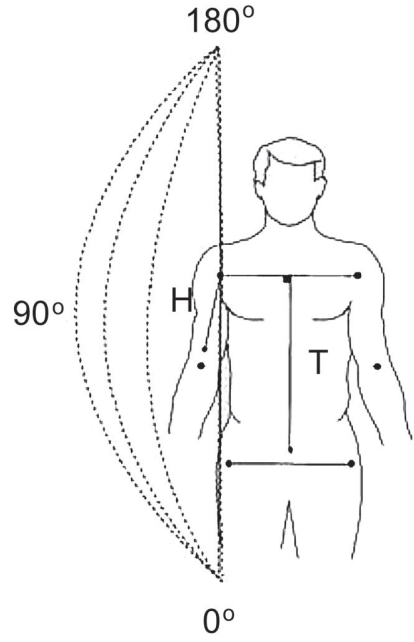

Vertical Elevation

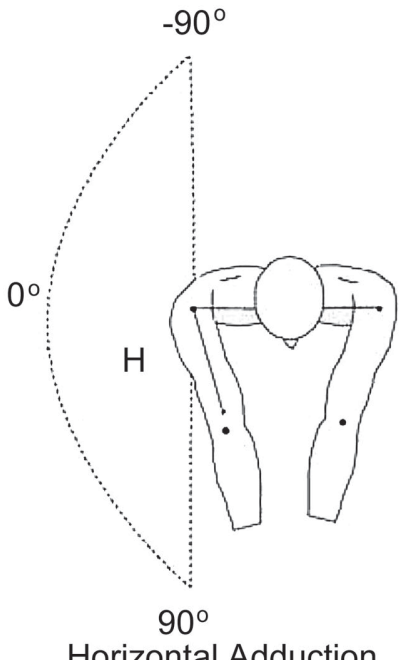

Horizontal Adduction

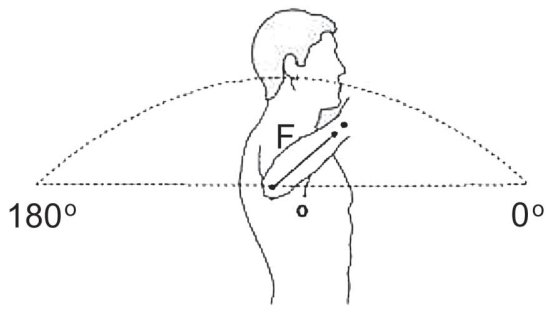

External Rotation
The first abduction phase is completed when it reaches $90^{\circ}$, then the motion is blocked because of the large tuberculus sticks against the upper glenoid rim. The humerus must turn outwards in order to overcome the mechanic blockage.

The second abduction phase is between $90^{\circ}$ and $150^{\circ}$. The entire shoulder girdle takes part in it, and the correlation between glenohumeral motions and the scapulothoracic joint is $1: 1$. The scapula rotation places the glenoid in a position in which the glenoid faces upwards. This rotation volume is $60^{\circ}$. The axial rotation of joints in both sides of the clavicle is $30^{\circ}$, and they also take part in the motion. The muscles participating in the second phase are the trapecius and the seratus anterior. The motion is limited around $150^{\circ}$ because of the resistance of the adductor muscles - latisimusdorsi and pectoralis major.
The third abduction phase is between $150^{\circ}$ and $180^{\circ}$. A motion, completed in the spinal column is required so that the arm can reach a vertical position. If only one arm is in abduction, the opposite spinal muscles shift the spinal column sidewards. When both arms are lifted, in order to keep their vertical position, the lumbar lordosis increases. This distribution of the arm elevation is artificial because the action of various muscles is actually performed smoothly.

\section{CONCLUSION:}

Knowing the biomechanics of the shoulder joint is essential both for preoperative planning and for the very technique of post fracture endoprosthesis replacement. Biomechanical indexes also serve for post operative estimation of the results achieved and appointing an optimal rehabilitation program.

\section{REFERENCES}

1. Neer CS 2nd. Displaced proximal humeral fractures. II. Treatment of three-part and four-part displacement. J Bone Joint Surg Am. 1970 Sep;52(6):1090-103. [PubMed]

2. Neer 2nd CS. Displaced proximal humeral fractures. I. Classification and evaluation. J Bone Joint Surg Am. 1970 Sep;52(6):1077-89. [PubMed]
3. Takov E, Tivchev P. [The Fracture diagnostics and treatment.] Venel, Bulgaria. 1996 [in Bulgarian]

4. Strip MB. X-ray confirmation of anterior shoulder instability. Orthop Trauma.1987; 2:225

5. Rao Mohandas K, Somayaji S, Ashwini L and Marpalli S. Origin of radial collateral artery from the posterior circumflex humeral artery in the quadrangular space of the shoulder region - an abnormality which could enhance the complications of quadrangular space syndrome. J Anatom Soc India. 2018;67:S17.

6. De Palma AF, Cantilli RA. Fractures of the upper and of the humerus. Clin Orthop. 1961; 20:73

7. Kapanji IA. The physiology of the joints. Ediburgh and London 
E\&A Livingstone.1970; 78

8. Koda, H. Influence of Muscle Fatigue on Three-Dimensional Scapular Kinematics During Repeated Arm Elevation. Biomed J Scient Tech Res. 2018; 10(5).

8. Koda H, Kai Y, Kida N, Murata S, Miura Y, Hideaki Fukushima H, et al. Influence of Muscle Fatigue on Three-Dimensional Scapular Kinematics During Repeated Arm Elevation. Biomed J Sci \& Tech Res. 2018; 10(5): 8142-46. [Crossref]

9. Jackson J, Mathiassen S and Liv P. Observer performance in estimating upper arm elevation angles under ideal viewing conditions when assisted by posture matching software. Appl Ergonomics. 2016; 55:208-15.

10. Huri $G$ and Paschos N. The shoulder. Cham, Switzerland: Springer; 2017

Please cite this article as: Mitkovski I. Biomechanical Principles of Shoulder Joint as a Basis of Post Fracture Endoprosthesis Replacement. J of IMAB. 2020 Jan-Mar;26(1):2910-2915.

DOI: https://doi.org/10.5272/jimab.2020261.2910

Received: 21/03/2019; Published online: 17/02/2020

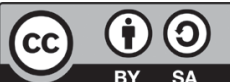

Addresses for correspondence:

Dr. Ivaylo Mitkovski, Medical University - Varna 55, Marin Drinov Str., 9002 Varna, Bulgaria, E-mail: ivo_hm@abv.bg 